This is the author's original manuscript (pre-refereed version) of the paper, and substantial changes are made in the final version. The final version will be published by Taylor \& Francis in Journal of Responsible Innovation. Please cite the final version at:

http://dx.doi.org/10.1080/23299460.2016.1216709

\title{
Responsible Innovation for Decent Nonliberal Peoples: A Dilemma?
}

\author{
Pak-Hang Wong \\ Lecturer \\ Department of Social Science, Hang Seng Management College \\ EMAll: phwong@hsmc.edu.hk
}

\begin{abstract}
It is hard to disagree with the idea of responsible innovation (henceforth, RI), as it enables policymakers, scientists, technology developers, and the public to better understand and respond to the social, ethical, and policy challenges raised by new and emerging technologies. RI has gained prominence in policy agenda in Europe and the United States over the last few years. And, along with its rising importance in policy-making, there is also a burgeoning research literature on the topic. Given the historical context of which Rl emerges, it should not be surprising that the current discourse on $\mathrm{RI}$ is predominantly based on liberal democratic values. Yet, the bias towards liberal democratic values will inevitably limit the discussion of RI, especially in the cases where liberal democratic values are not taken for granted. As such, there is an urgent need to return to the normative foundation of Rl, and to explore the notion of 'responsible innovation' from nonliberal democratic perspectives. Against this background, this paper seeks to demonstrate the problematic consequences of RI solely grounded on or justified by liberal democratic values. This paper will cast the argument in the form of a dilemma to be labelled as The Decent Nonliberal Peoples' Dilemma and use it to illustrate the problems of the Western bias.
\end{abstract}

KEYWORDS: Responsible Innovation, Liberal Democracy, Decent Nonliberal Peoples, Dilemma

ACKNOWLEDGEMENT: An early version of this paper was presented at the Climate Engineering Conference 2014 with the title "Responsible Innovation and the Danger of Technological Imperialism: A Case of Climate Engineering". The author wants to thank the audiences for insightful comments. The author also likes to thank Tom Wang and the colleagues at the Department of Social Science, Hang Seng Management College for extensive discussions on the ideas in the paper.

CONFLICT OF INTEREST: The author declares that he has no conflict of interest. 


\section{Responsible Innovation for Decent Nonliberal Peoples: A Dilemma?}

\section{Introduction}

It is hard to disagree with the idea of responsible innovation (henceforth, RI), i.e. to make scientific research and technological innovation "a transparent, interactive process by which societal actors and innovators become mutually responsive to each other with a view to the (ethical) acceptability, sustainability and societal desirability of the innovation process and its marketable products (in order to allow a proper embedding of scientific and technological advances in our society)" (von Schomberg 2012,50 ), as the objective of RI is to empower policy-makers, scientists, technology developers, and the public to better understand and respond to social, ethical, and policy challenges raised by new and emerging technologies. RI has gained prominence in policy agenda in Europe and the United States over the last few years. ${ }^{1}$ Along with its rising importance in policy-making, there is also a burgeoning academic research on the topic. ${ }^{2}$ Although the exact meaning of 'responsible innovation' remains under debate, existing understandings of RI are strongly associated with liberal democratic values, in particular freedom, equality and participation (see, e.g. von Schomberg 2012, 2013, 2014; Owen et al. 2012, 2013b; Stilgoe et al. 2013). ${ }^{3}$

Given the historical context of which RI emerges, it should not be surprising that the current discourse on RI is predominantly based on liberal democratic values (Owen et al. 2012; de Saille 2015). Yet, the bias towards these values will inevitably limit the discussion of RI, especially in cases where liberal democratic values are not taken for granted. ${ }^{4}$ More specifically, restricting the discussion of RI to be based on liberal democratic values will have unintuitive and undesirable consequences. In addition, neglecting the important questions about the plausible normative foundations of RI will

\footnotetext{
${ }^{1}$ For a historical overview of the idea of RI and related ideas, see Owen et al. (2012) and Stilgoe et al. (2013).

${ }^{2}$ For example, the Journal of Responsible Innovation is established in 2014 to devote to RI, see Guston et al (2014) for the rationales to start a journal on RI. Also, see Owen et al. (2013a), van den Hoven et al. (2014), and Koops et al. (2015) for some examples of recent work on RI.

${ }^{3}$ There are multiple ways to construe the 'liberal democratic values' and interpret 'freedom' and 'equality'. In this paper, I view them primarily via the liberal democratic notion of personhood, i.e. persons are viewed as independent, rational, and self-determining beings, who are the best and only candidates to determine their own course of life. Accordingly, individuals ought to be consulted and given justifications for any decisions that interfere with their ways of life, and their voices too ought to be weighted equally because individuals are seen as equal counterparts. Nussbaum succinctly points out that "at the heart of [the liberal democratic] tradition is a twofold intuition about human beings: namely, that all, just by being human, are of equal dignity and worth, no matter where they are situated in society, and that the primary source of this worth is a power of moral choice within them, a power that consists in the ability to plan a life in accordance with one's own evaluation of ends... [T] he moral equality of persons gives them a fair claim to certain types of treatment of debate within the tradition, but the shared starting point is that this treatment must do two closely related things. It must respect and promote the liberty of choice, and it must respect and promote the equal worth of persons as choosers" (Nussbaum 1999, 57). Following Nussbaum, I take freedom (as non-interference) and equality as the core values of liberal democratic worldview, and participation is a manifestation of these values.

${ }^{4}$ Of course, it too depends on the claim that liberal democratic values are not the only legitimate values to justify a political system. Indeed, if proponents of liberal democratic values insist those are the only legitimate values, then they might reject the consequences I will illustrate as 'problematic'. I shall return to this briefly when I discuss the possible responses to the dilemma.
} 
prevent us from seeing the problematic consequences that could be detrimental to the development of RI. Accordingly, there is an urgent need to return to the questions about the normative foundations of RI, and to explore the idea of 'responsible innovation' from nonliberal democratic perspectives.

Against this background, this paper seeks to demonstrate the problematic consequences of RI solely grounded on or justified by liberal democratic values. This 'Western' bias in RI has been briefly noted in the literature (see, e.g. Macnaghten et al. 2014), but the discussion here differs in that I will cast the argument in the form of a dilemma to be labelled The Decent Nonliberal Peoples' Dilemma and use it to illustrate the problems of the 'Western' bias. Before proceeding, it should be pointed out that the main objective of this paper is to make explicit one of the problems in the current discourse on $\mathrm{Rl}$, and thus to prevent it from being entrenched in the policy and scholarly discourse. Although the paper will outline some possible ways of out of the dilemma, I shall not pretend to provide any satisfactory solutions given the intricacies involved in resolving it.

\section{The Decent Nonliberal Peoples' Dilemma}

The Decent Nonliberal Peoples' Dilemma is based on the main assumption that RI requires liberal democratic values, and the main assumption can be interpreted in two ways. A strong interpretation of the main assumption refers to the view that the goals of RI are grounded on a specific set of values, which is liberal democratic in nature. In short, RI reflects a set of substantive values for research and innovation. Alternatively, a moderate interpretation of the main assumption refers to the view that the goals of RI are not inherently grounded on a specific set of values, but the frameworks, institutions, procedures, and/or practices of RI are nonetheless viewed as best justified by liberal democratic values. Although there are two interpretations of the main assumption, as it will become clear, they will leave us with the same dilemma. It should also be noted that the problematic consequences demonstrated in the dilemma will be more pronounced in the strong interpretation than in the moderate interpretation.

Let's now return to the dilemma. In what follows, I shall argue that if one accepts the main assumption, it entails either of the following consequences: (D1) decent nonliberal states (or, people who disagree with liberal democratic values) cannot have Rl; or, (D2) decent nonliberal states can have $\mathrm{RI}$ only if they introduce or are imposed liberal democratic values into their societies. Both (D1) and (D2), however, are problematic for RI. To resolve the dilemma, it is necessary to either reject the main assumption, or respond to (D1) or (D2).

Since the notion 'decent nonliberal states' plays an essential role in illustrating the problematic consequences of (D1) and (D2), it needs to be spelt out clearly. By 'decent nonliberal states', I follow John Rawls' understanding set out in The Law of Peoples (Rawls 1999)..$^{5}$ Rawls sets out two criteria for a nonliberal state to be considered as decent. Firstly, the nonliberal state should not be aggressive (Rawls 1999, 64). Secondly, the nonliberal state's system of law should (i) secure some basic human rights for its members in accordance with its common good idea of justice; (ii) it should also impose

\footnotetext{
${ }^{5}$ In The Laws of Peoples, Rawls' focuses on one form of decent nonliberal states, i.e. decent hierarchical societies, but he did not deny the possibility of other forms of decent nonliberal states (see, e.g. Rawls 1999, 4). In this paper, I shall use the term 'decent nonliberal states' to include all forms of decent societies that are not liberal democratic in nature.
} 
moral duties and obligations on all persons within the state, which those moral duties and obligations are derived from their common good idea of justice; and, (iii) the government should sincerely hold that the law is guided by a common good idea of justice (Rawls 1999, 65-67). Moreover, the decent nonliberal state has a 'decent consultation hierarchy' that looks after the important interests of all its members and provides an opportunity for different voices to be heard (Rawls 1999, 71-78).

Accordingly, (D1) is unwarranted. Given the decency of decent nonliberal states, i.e. the respect for (some) human rights, the moral duties and responsibilities of its members, and the common good idea of justice embraced by its members, together with the presence of the decent consultation hierarchy, it seems unreasonable to reject their capacity and willingness to ensure "the (ethical) acceptability, sustainability and societal desirability of the innovation process and its marketable products". Also, (D2) is either (politically) infeasible because it calls for a political overhaul of the nonliberal states, or immoral because it could raise an imperialistic concern in global science and technology policy.

It should be pointed out that I recognise well that Rawls' notion of 'decent nonliberal states' is not without its problems and limitations (see, e.g. Beitz 2000; Caney 2002). Yet, my argument for the dilemma only requires one to accept the existence of decent nonliberal states and their legitimacy. Nonetheless, I think Rawls' notion has the merit of foregrounding the existence of decent nonliberal states that are based on a different normative foundation and are too legitimate. In short, for those who disagree with Rawls' notion of 'decent nonliberal states', it can be viewed merely as a heuristic device in my argument.

\section{Responsible Innovation and Liberal Democratic Values}

As the Decent Nonliberal Peoples' Dilemma depends on the acceptance of the main assumption, it is essential to show that it is either explicitly or implicitly accepted by proponents of RI. In this section, I shall show that there is good reason to think it is indeed so in the current discourse on RI before moving on to the two horns of the dilemma.

Proponents of RI has acknowledged the strong affinity between RI and liberal democratic values (see, e.g. von Schomberg 2012, 2013, 2014; Owen et al. 2012, 2013b; Stilgoe et al. 2013; Stahl 2013; Valdivia \& Guston 2015). One of the clearest accounts on the relation between RI and democracy is offered by Rene von Schomberg $(2012,2013,2014)$, who argues that research and innovation need to be guided and governed by certain normative anchor points. Those normative anchors are conceptualised with substantial understandings of "ethical acceptability", "sustainability", and "social desirability" derived from the Treaty of European Union and the Charter of Fundamental Rights of the European Union. He also argues research and innovation processes should reflect a deliberative democracy through the inclusion and involvement of stakeholders and other interested parties in decision-making on science and technology. Here, public participation in science and technology is considered to be a normative requirement, and it draws on deliberative democracy that takes "outcomes [to be] legitimate to the extent they receive reflective assent through participation in authentic deliberation by all those subject to the decision in question" (Dryzek 2001, 651; also, see Benhabib 1996). Behind this ideal of deliberative democracy is a specific understanding of personhood: individuals are free (i.e. freedom as non-interference), and thus they ought to be consulted with and given justifications for decisions that could have significant impacts on their lives; and, individuals are 
equal, and thus their voices should be weighed equally and to be (actively) sought after in decisionmaking processes. ${ }^{6}$ Accordingly, von Schomberg's approach to RI appears to embrace a strong interpretation of the main assumption, as he invokes a set of substantive values to specify the goals of research and innovation, i.e. the EU fundamental values and the ideal of deliberative democracy. ${ }^{7}$

Richard Owen and his colleagues (Owen et al. 2012, 2013b; also, see Stilgoe et al. 2013) offer a different approach to RI that is sensitive to contexts in its application, and therefore is more open to other normative traditions. They characterise RI as "a continuous commitment to be anticipatory, reflective, inclusively deliberative, and responsive [in the process of research and innovation]" (Owen et al. 2013b, 29; original emphasis), and the four dimensions of RI are intended to identify and prescribe the procedures and practices that ensure research and innovation being (more) responsible. ${ }^{8}$ For instance, the dimension of anticipation requires "describing and analyzing those intended and potentially unintended impacts that might arise [... that] serve as a useful entry point for reflection on the purposes, promises, and possible impacts of innovation." (Owen et al. 2013b, 38). The dimension of reflection requires "reflecting on underlying purposes, motivations, and potential impacts, [and the limits of knowledge of research and innovation]" (ibid.). The dimension of deliberation refers to "inclusively opening up visions, purposes, questions, and dilemmas to broad, collective deliberation through processes of dialogue, engagement, and debate, inviting and listening to wider perspectives from publics and diverse stakeholders" (ibid.) that facilitate reframing of the issues and identifying potential conflicts. Finally, the dimension of responsiveness is to use the "collective process of reflexivity to both set the direction and influence the subsequent trajectory and pace of innovation, through effective mechanisms of participatory and anticipatory governance" (ibid.).

Bert-Jaap Koops (2015) rightly points out that Owen et al. do not aim at specifying goals for research and innovation with substantive values in their approach to RI, their aim instead is to make the process of research and innovation (more) responsible by introducing procedural values such as robustness, legitimacy, and inclusiveness into the process. In other words, their approach leaves open what goals should be pursued by research and innovation, and what substantive values ought to guide research and innovation. What their approach offers is this: with an eye to responsibility, how the goals of research and innovation are to be defined. So construed, Owen et al. approach differs significantly from von Schomberg approach in their attitude towards the main assumption, as they refrain from asserting that the goals of research and innovation need to be grounded on a specific set of substantive values.

Yet, the ideal of deliberative democracy remains central in Owen et al.'s approach. The four dimensions of RI identified by Owen et al. and the specific procedures and practices prescribed to realise those dimensions are in effect a manifestation of the ideal of deliberative democracy. Owen et al. conceive the objectives of $\mathrm{RI}$ as enabling us to reflect on the purposes of research and innovation, to explore and negotiate the social, ethical, and political boundaries of science and technology, to

\footnotetext{
${ }^{6}$ For a more extensive discussion of the relation between public participation and the liberal democratic view of personhood, see Wong (2013).

${ }^{7}$ A similar account of RI, which too is based on the European values, is provided by van den Hoven et al. (2013, 23-24).

${ }^{8}$ It is worth noting that the terms for the four dimensions are "anticipation", "reflexivity", "inclusion", and

"responsiveness" in Stilgoe et al. (2013), thus are different from the terms used by Owen et al. (2013b), but their explanation for the four dimensions does not differ notably.
} 
proactively guide research and innovation to desirable ends, and to be open-minded, adaptive, and responsive to the changing environment as well as various views, perspectives and framings of issues in science and technology. In other words, they view RI as an opening-up of science and innovation for public deliberation and public decision-making. At the same time, they also assert that these objectives introduce the ideal of deliberative democracy in their approach to RI, i.e. being deliberative is required to achieve them (Owen et al. 2013, 35-38). In effect, Stilgoe describes this approach as a democratisation of the governance of intent that seeks not only to open up the research agendas for the public to discuss and deliberate but also to open up the discussion and decision-making of the very purpose(s) of research and innovation themselves (Stilgoe 2011; also see Owen 2013). In short, even though Owen et al.'s approach does not specify the goals of research and innovation with liberal democratic values, the procedures and practices prescribed by their approach are nonetheless to be justified by the key democratic values that every individuals has standing to participate in (informed) public deliberation and that legitimacy of a decision and/or policy is derived from the public deliberation. ${ }^{9}$ As such, it is fair to conclude that Owen et al. do endorse a moderate interpretation of the main assumption.

It is important to point out that I am not disagreeing with the objectives of RI as characterised in Owen et al.'s approach, what I am disagreeing with is to overemphasise the importance of (deliberative) democratic values as the best, if not the only, values for accomplishing the objectives of $\mathrm{RI}$ and thereby viewing those values as required by RI. Particularly, how the objectives of RI are best realised is an empirical question, and it depends on various contingent factors including the social and political conditions, which do not always favour liberal democratic values and practices. Accordingly, liberal democratic values may not always be the best set of values to ground the goals of RI.

Here, Owen et al. could argue that public deliberation - or, more generally, deliberative democracy - is the only means of governance that properly ensure the legitimacy of research agendas, which, in turn, provides a normative justification for their approach to RI (Stilgoe et al. 2013, 1576-1577). ${ }^{10}$ However, as Dean J. Machin (2012) rightly points out that (political) legitimacy is not derived from democratic values per se, but through satisfying the requirements of (i) horizontal equality between individuals, (ii) acceptable vertical inequality between decision-makers and the public, (iii) publicity, i.e. decisions should be made in a transparent and non-secret manner, and (iv) individuals having some institutionalised opportunities for a voice in decisions that affect them. Accordingly, nonliberal

\footnotetext{
${ }^{9}$ Their commitment to the values of deliberative democracy (or, democratisation) is most explicitly stated in Stilgoe et al., where they state "[o]ur approach [...] has concentrated on the means of governances such that an improved - more democratic or more legitimate - consideration of ends become possible. [...] In this sense, we have second-order normative commitments to democratisation, which we see as vital for the good governance of science and innovation" (Stilgoe et al. 2013, 1577; my emphasis).

${ }^{10}$ Stirling (2005) has summarised the three rationales for public participation (or public deliberation) as "normative", "instrumental", and "substantive", i.e. "[f]rom a normative view, participation is just the right thing to do. From an instrumental perspective, it is a better way to achieve particular ends. In substantive terms, it leads to better ends" (Stirling 2005, 220). It is, however, unclear why public participation is in itself a (morally) right thing to do. For Stirling, it is because public participation satisfies "Habermasian principles of 'ideal speech', with Rawlsian notions of 'public reason' and with a multitude of derived evaluative criteria held ideally to be associated with effective engagement in social appraisal. [...] In short, under [the] normative democratic view, participation is self-evidently a good thing in its own right, without the need for further justification" (Stirling 2005: 221). However, Stirling has not discussed whether this apply when liberal democratic values are not favoured by the public.
} 
democratic political systems are also legitimate so long as they can satisfy (i)-(iv). ${ }^{11}$ More importantly, if Machin is right, then there is little reason to hold that RI requires (deliberative) democratic values, or that (deliberative) democracy is the only mean of governance that can properly ensure the legitimacy of research agendas.

Nothing above has conclusively demonstrated non-European values and/or nonliberal democratic values are inherently incompatible with the existing approaches to RI. Indeed, it is certainty true that von Schomberg has not explicitly rejected the possibility of non-European values being the sources of Rl's normative anchor points, or that Owen et al.'s approach is necessarily incompatible with nonliberal democratic institutions. However, at the moment, I fail to see any serious attention and detailed discussions of non-European values - or, more broadly, nonliberal democratic values - in the current discourse on RI. ${ }^{12}$ While the lack of attention and discussion might due to the relative newness of the concept of RI, I reckon the lack of attention and discussion given to other normative traditions in the discourse of RI could lead to an unhealthy negligence of the importance and relevance of alternative normative foundations for RI.

\section{The First Horn of the Dilemma: Can Decent Nonliberal Peoples Have Responsible Innovation?}

The previous section attempts to illustrate the prominence of the main assumption in the current discourse on RI through von Schomberg's and Owen et al.'s approaches. It is true that the discussion has not shown that every proponent of RI endorses the main assumption, but the emphasis on European and/or liberal democratic values in the current discourse and the lack of attention to nonEuropean and nonliberal democratic values have provided adequate reasons to worry that other normative foundations have been neglected in the discussion. This is worrying because the omission of nonliberal democratic perspectives and the acceptance of the main assumption lead to the Decent Nonliberal Peoples' Dilemma.

The first horn of the Decent Nonliberal Peoples' Dilemma asserts that (D1) decent nonliberal states cannot have RI. (D1) is the logical consequence of endorsing the main assumption, which states that RI requires liberal democratic values either to ground the goals of research and innovation, or to justify the frameworks, institutions, procedures, and/or practices with them. Accordingly, by definition, nonliberal peoples are incapable of research and innovation responsibly because they do not have the proper set of values to ground the goals of research and innovation, nor they can justify RI with their normative foundations.

There are, however, good reasons to reject (D1). For instance, it is unclear why public participation, i.e. a key (semi-)institutional practice in RI based on liberal democratic values, cannot be justified merely on instrumental grounds or by other normative traditions (see, e.g. Wong 2013; also see Chan

\footnotetext{
${ }^{11}$ Machin (2012) argues that Rawls's formulation of decent consultation hierarchy does not satisfy the requirement of horizontal equality because it does not represent individuals qua individuals, but he too points out that if it can be adequately modified to represent individuals qua individuals, then it will satisfy the requirement. In this paper, the specific details about decent consultation hierarchy are irrelevant; what is important is that there are nonliberal democratic political systems that are as legitimate as liberal democratic political systems.

12 One notable exception is Arnaldi et al. (2015).
} 
2007; Angle 2009). It is also unclear why other normative traditions are incapable of guiding research and innovation with an eye on "(ethical) acceptability, sustainability and societal desirability".

For example, the idea of Minben ("the people as the basis") in Confucian political philosophy places an overt emphasis on the government's (or, ruler's) responsibility for the welfare of the people. A central tenet in Confucian political philosophy is that (political) legitimacy of the government is based on the will of the people, but it regards the relationship between the government and the public to be analogous to the parent-son relationship and takes it to be paternalistic and meritocratic, i.e. the government (or ruler) should not be shied away from promoting their view(s) of the good to the people (see, e.g. Murthy 2000; Wang \& Titunik 2000; Bai 2008). ${ }^{13}$ Accordingly, the Minben philosophy of Confucianism can too provide a normative foundation to include the public interests in science and technology policy agenda-settings through public dialogues, as public dialogues enable the government to better understand the needs of the people and being more responsive to those needs; however, public participation's role in Confucian political philosophy remains essentially advisory, and the final decisions are to be made by the government authoritatively based on its conception of the good (see, Bai 2008; He \& Warren 2011). In this respect, the Minben philosophy of Confucianism is in opposition to the liberal democratic values of freedom as non-interference and equality as voices having the same weight (Elstein 2010).

This is not to assert any normative traditions can be used in grounding or justifying RI without further adjustments and qualifications. In fact, a more detailed discussion of Confucian political philosophy and the idea of Minben is required to fully elaborate the plausibility of a Confucian framework of RI. Yet, it does assert there is little reason to reject the possibility that other normative traditions can ground and justify a version of RI based on their values. In short, (D1) is unwarranted.

\section{The Second Horn of the Dilemma: Some Imperialistic Concerns}

Another consequence entailed by the main assumption is (D2), i.e. decent nonliberal people have to accept liberal democratic values in order to have RI, where liberal democratic values can be introduced to decent nonliberal states either (i) by the decent nonliberal states' own acceptance of those values, or (ii) by an imposition of those values from liberal democratic states. Both (i) and (ii), however, are problematic.

First, (i) suggests an overhaul of the value system is required in order to introduce RI to decent nonliberal states (which, after accepting the liberal democratic values, will no longer be nonliberal states). The problem with this is that (i) seems infeasible. Particularly, a replacement and/or addition of basic values - if they happen at all - require an extended period of time, and the local (traditional) values often leave an imprint on the value system and shape the cultural change (Inglehart \& Baker 2000). If RI is a pressing issue in science and technology policy, it would be impractical to require decent nonliberal states to accept liberal democratic values before developing their version(s) of RI. More importantly, as I have argued, other normative traditions can also provide the normative basis of RI. Accordingly, liberal democratic values might not be necessary after all.

\footnotetext{
${ }^{13}$ The will of the people, in turn, (re)presents the will of heaven, which is the ultimate source of (political) authority. For an overview of the idea of Minben in Confucian political philosophy, see, Wang \& Titunik (2000).
} 
Second, (ii) is also problematic, as the imposition of values from outside can be view as morally problematic. For instance, the imposition of values can be achieved through direct intervention, but it is unclear how direct intervention can be justified in the context of RI. Particularly, if decent nonliberal states are legitimate, and they do not violate a minimal set of rights of their community members, a direct intervention fails to tolerate and respect diversity in values, which are the core principles in liberalism itself (Rawls 1999). This is, of course, not to suggest the principles of toleration and respect are without criticisms (see, e.g. Tan 1998; Beitz 2000; Buchanan 2000); however, the common objections to the principles tend to focus on considerations about the right and the just, whereas RI focuses primarily on what can research and innovation contribute to the good of the people. It is, therefore, more difficult to reject the principles in the context of RI without raising imperialistic concerns, as our world is characterised by a plurality of the good life, i.e. there are diverse, and possibly conflicting, views of the good life that are equally valid, it seems that there is no good justification to impose a specific view of the good on others. ${ }^{14}$

Alternatively, the acceptance of liberal democratic values can be initiated indirectly with institutionalisation, e.g. introduction of global standard(s) for research and innovation (Wickson \& Forsberg 2015; also, see Waldby \& Slater 2008). Standardisation can encourage, or indeed require, scientists and technology developers to follow a set of procedures if they are to be accepted as members of the global network of research and innovation. Liberal democratic values can then be introduced to decent nonliberal states with standardisation formulated on the basis of those values. ${ }^{15}$ So construed, those who do not accept liberal democratic values will be excluded from international collaborations and will be barred from the global market because they do not satisfy the international standard(s) of RI. Hence, standardisation is an inherently value-laden project, as it designates the normative criteria for inclusion to the global network. Here, one of the major adverse implications of the introduction of value-laden standard(s) of RI appears to be the delegitimisation of the plausibility of RI based on local values, especially when those values come into conflict with the liberal democratic values, as the local values (or, the RI based on local values) do not enable scientists and technology developers to be recognised as members of the global network of research and innovation.

Of course, it is possible to include local values (and decent nonliberal states) in the creation of international standard(s); however, to do so their legitimacy and the importance of their values will have to be properly acknowledged. In other words, the main assumption that RI requires liberal democratic values has to be rejected, and the negligence of other normative traditions cannot be sustained if we intend to include other normative traditions into the creation of international standard(s).

\footnotetext{
${ }^{14}$ Alternatively, the "plurality of good life" can be illustrated with Rawls' "the fact of reasonable pluralism," i.e. "a pluralism of comprehensive religious, philosophical, and moral doctrines [and, more importantly,] a pluralism of incompatible yet reasonable comprehensive doctrines" (Rawls 1993, p. xvi). Given the reasonableness of the comprehensive doctrines, it seems unjustified to reject other's comprehensive doctrines in favour of one's own.

${ }^{15}$ There is an important question as to whether it is indeed possible to have a standard (or, a set of procedures) representing a specific set of values, e.g. liberal democratic values. This is an important question for those who are in favour of standardisation in RI, but it has little implication to my argument. What is important to my argument is that standard(s) of RI is (are) not neutral, and standardisation inevitably imposes foreign values through institutionalisation.
} 


\section{Conclusion}

To reiterate, the aim of this paper is to illustrate the Decent Nonliberal Peoples' Dilemma resulting from overemphasising liberal democratic values in RI. I start with the reminder that there are decent nonliberal states, which are legitimate but they are not always in alignment with the liberal democratic values. I then point out that if the proponents of RI neglect the normative foundations of decent nonliberal states, or take liberal democratic values as the only legitimate normative foundation for RI, they will face the problematic consequences characterised by the dilemma.

It is important not to over-interpret the arguments in this paper, however. Particularly, the aim of this paper is not to prove the legitimacy of nonliberal states - decent or otherwise. Instead, the paper attempts to show that if decent nonliberal states are legitimate, and their values are too fitting as the normative foundation of $\mathrm{RI}$, then the proponents of RI need to take them more seriously in the discourse on $\mathrm{Rl}$, and to return to the fundamental question(s) concerning the normative foundation of RI.

For those who think liberal democratic values of freedom and equality are essential to RI, they will have to demonstrate why those values are indeed essential to RI. Here, they may refer to the recent works on cosmopolitanism to support their position (see, e.g. Beitz 1979; Pogge 1992; Tan 2004; Caney 2005). This is not the place to discuss the merits and problems of cosmopolitanism, but it is a useful reminder for the need to answer the fundamental question(s) concerning the normative foundation of RI.

For those who wish to reject the main assumption and to open up RI to other normative traditions, they will have to answer two challenges arise from the inclusion of other normative traditions. The first challenge is theoretical, i.e. the inclusion of other normative traditions invite relativism (or, impotent pluralism) in that it is unclear what values to be included in RI, and what, if any, value(s) should take priority in case of conflict. ${ }^{16}$ And, the second challenge is practical, i.e. there is little research on alternative normative foundations for RI. Indeed, other normative traditions are rarely included in the policy and scholarly discourse on RI. In this respect, this paper can be viewed as a call for more extensive research on "non-Western" ethics and political philosophy and their relevance to RI. It is only through more careful studies of other normative traditions we could determine if, and how, they can contribute to RI.

\section{References}

Angle, S. (2009). The Necessity of Participation: Towards a Contemporary Confucian Politics. Seeking Truth 4, 3338.

Arnaldi, S., Quaglio, G., Ladikas, M., O'Kane, H., Karapiperis, T., Srinivas, K.R., Zhao, Y. (2015). Responsible Governance in Science and Technology Policy: Reflections from Europe, China and India. Technology in Society 42, 81-92.

Bai, T. (2008). A Mencian Version of Limited Democracy. Res Publica 14, 19-34.

Beitz, C. (1979). Political Theory and International Relations. Princeton: Princeton University Press.

Beitz, C. (2000). Rawls's Law of Peoples. Ethics 110 (4), 669-696.

\footnotetext{
${ }^{16}$ In addition to the charge of relativism, those who incline towards this position will also have to answer the arguments from the proponents of global democracy and cosmopolitanism.
} 
Benhabib, S. (1996). Toward a Deliberative Model of Democratic Legitimacy. In: S. Benhabib (ed.), Democracy and Difference: Contesting the Boundaries of the Political (pp. 67-94). Princeton, NJ: Princeton University Press.

Buchanan, A. (2000) Rawls's Law of Peoples: Rules for a Vanished Westphalian World. Ethics 110 (4), 697-721.

Caney, S. (2002). Cosmopolitanism and the Law of Peoples. Journal of Political Philosophy 10 (1), 95-123.

Caney, S. (2005). Justice Beyond Borders: A Global Political Theory. Oxford: Oxford University Press.

Chan, J. (2007). Democracy and Meritocracy: Toward a Confucian Perspective. Journal of Chinese Philosophy 34, 171-93.

de Saille, S. (2015). Innovating Innovation Policy: The Emergence of 'Responsible Research and Innovation'. Journal of Responsible Innovation 2 (2), 152-168.

Dryzek, J. S. (2001). Legitimacy and Economy in Deliberative Democracy. Political Theory 29 (5), 651-669.

Elstein, D. (2010). Why Early Confucianism Cannot Generate Democracy. Dao 9 (4), 427-443.

Guston, D.H., Fisher, E., Grunwald, A., Owen, R., Swierstra, T. , van der Burg, S. (2014). Responsible Innovation: Motivations for a New Journal. Journal of Responsible Innovation 1 (1), 1-8.

He, B., Warren, M. (2011). Authoritarian Deliberation: The Deliberative Turn in Chinese Political Development. Perspectives on Politics 9 (2), 269-289.

Inglehart, R., Baker, W.E. (2000). Modernization, Cultural Change, and the Persistence of Traditional Values. American Sociological Review 65, 19-51.

Koops, B.-J., Oosterlaken, I., Romijn, H., Swierstra, T., van den Hoven, J. (2015). Responsible Innovation 2: Concepts, Approaches, and Applications: Dordrecht: Springer.

Machin, D.J. (2012). Political Legitimacy, the Egalitarian Challenge, and Democracy. Journal of Applied Philosophy $29(2), 101-117$.

Macnaghten, P., Owen, R., Stilgoe, Wynne, B., Azevedo, A., de Compos, A., Chilvers, J., Dagnino, R., di Giulioh, G., Frow, E., Garvey, B., Groves, C., Hartley, S., Knobel, M., Kobayashi, E., Lehtonen, M., Lezaun, J., Mello, L., Monteiro, M., Pamplona da Costa, J., Rigolin, C., Rondani, B., Staykova, M., Taddei, R., Till, C., Tyfield, D., Wilford, S., Velho, L. (2014). Responsible Innovation across Borders: Tensions, Paradoxes and Possibilities. Journal of Responsible Innovation 1 (2), 191-199.

Murthy, V. (2000). The Democratic Potential of Confucian Minben Thought. Asian Philosophy, 10 (1), 33-47.

Nussbaum, M. (1999). Sex and Social Justice. New York: Oxford University Press.

Owen R. (2013). Techno-visionary Science and the Governance of Intent. Science, Technology and Innovation Studies 9 (2), 95-103.

Owen, R., Macnaghten, P., Stilgoe, J. (2012). Responsible Research and Innovation: from Science in Society to Science for Society, with Society. Science and Public Policy 39, 751-760.

Owen, R., Bessant, J., Heintz, M. (eds.) (2013a). Responsible Innovation: Managing the Responsible Emergence of Science and Innovation in Society. Chichester: Wiley-Blackwell.

Owen, R., Macnaghten, P., Stilgoe, J., Gorman, M., Fisher, E., Guston, D. (2013b). A Framework for Responsible Innovation. In: R. Owen, J. Bessant and M. Heintz (eds.), Responsible Innovation: Managing the Responsible Emergence of Science and Innovation in Society (pp. 27-50). Chichester: Wiley-Blackwell.

Pogge, T. (1992). Cosmopolitanism and Sovereignty. Ethics 103, 48-75

Rawls, J. (1993). Political Liberalism. New York: Columbia University Press.

Rawls, J. (1999). The Law of Peoples. Cambridge, Mass.: Harvard University Press.

Stahl, B.C. (2013). Responsible Research and Innovation: The Role of Privacy in an Emerging Framework. Science and Public Policy, 40 (6), 708-716.

Stilgoe, J. (2011). A Question of Intent. Nature Climate Change 1, 325-326. 
Stilgoe, J., Owen, R., Macnaghten, P. (2013). Developing a Framework for Responsible Innovation. Research Policy 42 (9), 1568-1580.

Stirling A. (2005). Opening up or closing down? Analysis, Participation and Power in the Social Appraisal of Technology. In: M. Leach, I. Scoones, and B. Wynne (eds), Science and Citizen: Globalization and the Challenge of Engagement (pp. 218-231). London: Zed

Tan, K.-C. (1998). Liberal Toleration in Rawls's Law of Peoples. Ethics 108 (2), 276-295.

Tan, K.-C. (2004) Justice Without Borders: Cosmopolitanism, Nationalism, and Patriotism. Cambridge: Cambridge University Press.

van den Hoven, J., Doorn, N., Swierstra, T., Koops, B.-J., Romijn, H. (2014). Responsible Innovation 1: Innovative Solutions for Global Issues. Dordrecht: Springer.

van den Hoven, J., Jacob, K., Nielsen, L., Roure, F., Rudze, L., Stilgoe, J. (2013). Options for strengthening responsible research and innovation Report of the Expert Group on the State of Art in Europe on Responsible Research and Innovation. Luxembourg: Publications Office of the European Union. Available Online: https://ec.europa.eu/research/swafs/pdf/pub public engagement/options-forstrengthening en.pdf

von Schomberg, R. (2012). Prospects for Technology Assessment in a Framework of Responsible Research and Innovation. In: M. Dusseldorp and R. Beecroft (eds), Technikfolgen Abschätzen Lehren: Bildungspotenziale Transdisziplinärer Methoden (pp. 39-61). Wiesbaden: VS Verlag.

von Schomberg, R. (2013). A Vision of Responsible Research and Innovation. In: R. Owen, J. Bessant and M. Heintz (eds.), Responsible Innovation: Managing the Responsible Emergence of Science and Innovation in Society (pp. 51-74). Chichester: Wiley-Blackwell.

von Schomberg, R. (2014). The Quest for 'Right Impacts of Science and Technology: A Framework for Responsible Research and Innovation. In J. van den Hoven, N. Doorn, T. Swierstra, B.-J. Koops and H. Romijn (eds.), Responsible Innovation 1: Innovative Solutions for Global Issues (pp. 33-50). Dordrecht: Springer.

Valdivia, W., Guston, D. (2015). Responsible Innovation: A Primer for Policymakers. Available Online: http://www.brookings.edu/ /media/research/files/papers/2015/05/05-responsible-innovation-valdiviaguston/valdivia-guston responsible-innovation v9.pdf

Waldby, C., Slater, B. (2008). Global Governance in Human Embryonic Stem Cell Science: Standardisation and Bioethics in Research and Patenting. Studies in Ethics, Law, and Technology 2 (1). Available Online: http://dx.doi.org/10.2202/1941-6008.1031

Wang, E., Titunik, R.F. (2000). Democracy in China: The Theory and Practice of Minben. In S. Zhao (ed.), China and Democracy: The Prospect for a Democratic China (73-88). New York: Routledge.

Wickson, F., Forsberg, E,-M. (2015) Standardising Responsibility? The Significance of Interstitial Spaces. Science and Engineering Ethics 21 (5), 1159-1180.

Wong, P.-H. (2013). The Public and Geoengineering Decision-Making: A View from Confucian Political Philosophy. Techné: Research in Philosophy and Technology 17 (3), 350-367. 